\title{
Low-Cost Position Sensorless Switched Relutance Motor Drive Using a Single-Controllable Switch Converter
}

\author{
Hyong-Yeol Yang*, Jaehyuck Kim ${ }^{\dagger}$, and R. Krishnan** \\ ${ }^{*}$ Dept. of Electrical Engineering, Honam University, Gwangju, Korea \\ ${ }^{\dagger}$ Dept. of Electrical Engineering, Wonkwang University, Jeonbuk, Korea \\ ${ }^{* *}$ Dept. of Electrical Engineering, Virginia Polytechnic Institute and State University, Blacksburg, VA, USA
}

\begin{abstract}
Elimination of rotor position sensors mechanically coupled with the rotor shaft is attractive to variable speed drives primarily due to increased system reliability and cost reduction. In this regard, search for a simple and robust position sensorless control has been intensified in past few years specifically for low-cost, high-volume applications such as home appliances. This paper describes a new parameter insensitive position sensorless control for switched reluctance motor (SRM) drives satisfying such a need in this market segment. Two consecutive switch-on times of the controllable switch in hysteresis current control are compared to estimate the rotor position and speed. The proposed sensorless control algorithm is very simple to implement since it does not depend on extensive computation or any additional hardware. In addition, the proposed method is robust in that its dynamic performance is least affected by system parameter variations. The proposed approach is demonstrated on a single-controllable-switch-converterdriven SRM with two-phases that lends itself to a system with low cost and compact packaging which comes close to the intended applications. Analysis and simulation results followed by experimental verification are presented to demonstrate the feasibility of the proposed sensorless control method.
\end{abstract}

Key Words: Low cost converter, Sensorless control, Switched reluctance motor, Variable speed drives

\section{INTRODUCTION}

Simple, rugged, and low-cost structure, along with highefficiency and high-reliability features makes the switched reluctance motor (SRM) a viable solution to many variable speed drives applications ranging from high-performance traction to low-cost home appliances [1]. Cost minimization is an important factor in successful realization of a motor drive system, specifically in low-cost, high-volume applications. Several SRM drives [2]-[5] have been proposed in an effort to achieve cost reduction both in machine and converter topologies. Further cost reduction is possible by eliminating the rotor position sensor which requires mounting labor and space, and hence adds to cost and size of the drive system. Various methods for position sensorless estimation and control have been proposed hitherto; however, their selection primarily depends on specific application and operating speed. Most position sensorless techniques in SRMs utilize the SRMs' unique relationship between the flux linkage (or inductance), rotor position, and phase current. Therefore, the key to successful

Manuscript received Aug. 31, 2011; revised Dec. 12, 2011

Recommended for publication by Associate Editor Jang-Mok Kim.

$\dagger$ Corresponding Author: jaehkim@wku.ac.kr

Tel: +82-63-850-6733, Fax: +82-63-850-7315, Wonkwang University

* Dept. of Electrical Engineering, Wonkwang University, Korea

** Dept. of Electrical Engineering, Virginia Tech, USA realization of a sensorless SRM drive is the generation of the reliable flux linkage or inductance estimate during operation.

The flux-current methods in [6], [7] estimate flux linkage by open-loop integration with measured terminal signals (voltage and current) and then extracts rotor position from the stored three-dimensional data between flux, current, and rotor position. While this approach is simple and more suitable for high speed, single-pulse operation, it needs a large amount of lookup tables and can have significant estimation errors at low speed, chopping mode operation where the effect of the winding resistance becomes significant. Flux or inductance variation can be obtained directly using sensing coils [8], [9], but the extra coils may cause coupling with main power signals and add to the manufacturing cost and effort.

Observer-based methods [10]-[12] utilize model-based estimators to estimate state variables such as flux, speed, or rotor position by real-time computation with measured phase voltage and currents. Although these methods are valid over wide speed range, substantial real-time computation and high sensitivity to parameter variation are their major drawbacks.

Intelligent control such as neural networks and fuzzy logic [13]-[15] provides inherent capability for adaptation of parameter variation and disturbances; however, it requires off-line training and substantial real-time computation.

Inductance based methods exploit the relationship between 


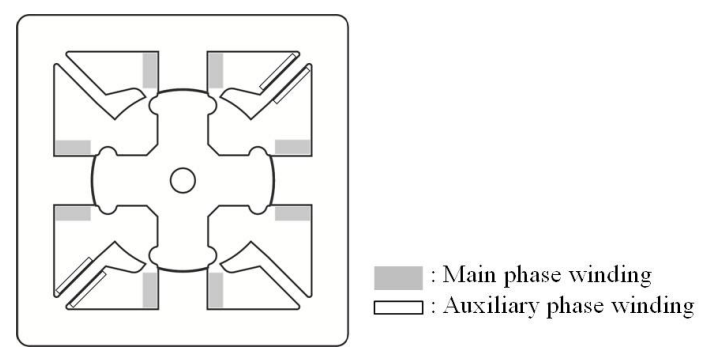

Fig. 1. Prototype motor configuration.

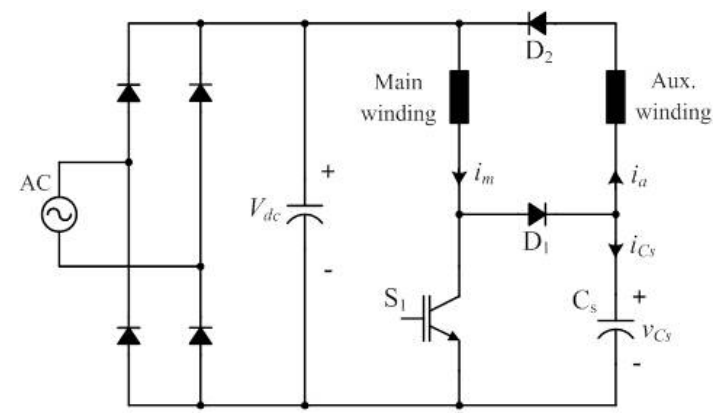

Fig. 2. Single-controllable-switch converter.

the phase self (or incremental) inductance and rotor position for each excitation current. The phase inductance can be modeled analytically using the Fourier series and curve- fitting of some off-line measurements for real-time estimation of the rotor position [16], [17]. The phase inductance can also be estimated by injecting a diagnostic signal into an inactive phase [18], [19], but negative torque production and knocking sound by injected current into the sensing phase are among the drawbacks of this method.

Current waveform monitoring methods [20], [21] are based on the idea that the rate of change of current depends on the incremental inductance, which in turn depends on the rotor position. The incremental inductance is calculated using the voltage equation with measured current increment and rise or fall time and then the rotor position is obtained from the stored incremental inductance-current-position data. However, the incremental inductance is bi-valued within half a rotor pole pitch at higher currents, hence loosing oneto-one relationship with the rotor position. In addition, the accuracy of the calculation of the incremental inductance is deteriorated by the effects of winding resistance and backEMF at higher speed, hence requiring somewhat complicated compensation. Gallegos-Lopez et al.[22] proposed a simple approach to detect the rotor position where a rotor pole and a stator pole begin to overlap by monitoring the rate of change of current using an analog circuit, but not suitable for lowand medium-speed operation.

The fundamental idea of the proposed sensorless control is that the rate of change of current depends on the phase selfinductance, which in turn depends on the rotor position. In this regard, this approach is similar to the methods in [20] and [21]. However, the proposed method requires neither online calculation of the inductance nor mapping of inductanceposition relationship, and hence no off-line measurement or lookup table is necessary. Instead, by comparing two consecutive switching times in a chopping current waveform, proper commutation of the motor as well as the speed estimation can be achieved. Since the inductance-current-position relation is extracted without solving the voltage equation, the proposed method is simple to implement and insensitive to system parameter variations.

\section{Motor Drive System And Modeling}

\section{A. Motor and Power Converter}

The motor configuration employed in the proposed study is shown in Fig.1. The motor has eight salient poles (four main and four auxiliary) on the stator and four salient poles on the rotor. While the motor has two phases, they are not identical. The main phase produces the majority of the torque, whereas the auxiliary phase is mainly intended for starting and speed reversal and hence four-quadrant operation is possible. In the current experimental system, only one set of diametrically opposite auxiliary windings are used. Additional information on magnetization and torque characteristics is discussed in [2]. The single-controllable-switch-converter [3] shown in Fig.2 has been chosen to drive the motor. The converter has only one controllable switch and two diodes in total for driving the two-phase SRM, hence making the drive's electronics very compact and inexpensive. The key features and basic operating principles of the converter are:

1) A full-bridge rectifier and capacitor $\mathrm{C}_{d c}$ form a dc link to supply energy to main phase.

2) Diode $D_{2}$ is optional; hence it can be eliminated to achieve further cost reduction.

3) The main phase is controlled by switch S1, whereas the auxiliary phase is indirectly controlled by capacitor $\mathrm{C}_{s}$ voltage and parameters of auxiliary winding $\left(\mathrm{R}_{a}, \mathrm{~L}_{a}\right)$.

4) When $S_{1}$ is turned on, the main phase is energized.

5) When $S_{1}$ is turned off, current in the main phase flows through $\mathrm{D}_{1}$ and then either flows to charge Cs or circulates through the auxiliary phase, $\mathrm{D}_{1}$, and $\mathrm{D}_{2}$.

6) The energy dumped into $C_{s}$ goes in part to excite auxiliary phase and is in part returned to dc link. In this regard, $\mathrm{C}_{s}$ can be seen as an energy recovery capacitor as well as a turn-off snubber along with $\mathrm{D}_{1}$ for $\mathrm{S}_{1}$.

\section{B. Derivation of System Equations}

Neglecting mutual coupling between the phase windings, the phase voltage equation of an SRM is given by

$$
v_{p h}=R_{p h} i_{p h}+\frac{d \lambda_{p h}}{d t}
$$

where $v_{p h}, i_{p h}$, and $R_{p h}$ are the phase voltage, phase current, and winding resistance, respectively. The phase flux linkage, $\lambda_{p h}=L\left(\theta, i_{p h}\right) i_{p h}$ is a nonlinear function of the phase current, $i_{p h}$ and rotor position, $\theta$. Upon examining all the switching states of the switch and diodes of the converter, it is seen that there are five possible modes of operation and they are summarized in Table I. Based on these modes, drive system equations to model the operation of the motor combined with the converter can be derived. The two sets of state equations are derived to describe each mode of operation with respect to the switching states of S1. Note that the dc link and the power 
TABLE I

MODES OF OPERATION

\begin{tabular}{c|c|c|c|c|c|c}
\hline Mode & S1 & D1 & D2 & $i_{m}$ & $i_{a}$ & $i_{C s}$ \\
\hline 1 & On & Off & On & $>0$ & $>0$ & $<0$ \\
\hline 2 & On & Off & Off & $>0$ & $=0$ & $=0$ \\
\hline 3 & Off & On & On & $>0$ & $>0$ & $=0$ \\
\hline 4 & Off & On & Off & $>0$ & $=0$ & $>0$ \\
\hline 5 & Off & Off & On & $=0$ & $>0$ & $<0$ \\
\hline
\end{tabular}

devices are assumed to be ideal; hence, the dc link voltage is constant and the device voltage drops are ignored.

1) Switch S1 ON (mode 1, 2):

$$
\begin{gathered}
\frac{d \lambda_{m}}{d t}=V_{d c}-R_{m} i_{m} \\
\frac{d \lambda_{b}}{d t}=v_{C s}-V_{d c}-R_{a} i_{a} \\
\frac{d v_{C s}}{d t}=\frac{i_{C s}}{C_{S}}=\frac{-i_{a}}{C_{S}}
\end{gathered}
$$

2) Switch S1 OFF (mode 3, 4, 5)::

$$
\begin{gathered}
\frac{d \lambda_{m}}{d t}=V_{d c}-v_{C s}-R_{m} i_{m} \\
\frac{d \lambda_{a}}{d t}=v_{C s}-V_{d c}-R_{a} i_{a} \\
\frac{d v_{C s}}{d t}=\frac{i_{C s}}{C_{S}}=\frac{i_{m}-i_{a}}{C_{S}} .
\end{gathered}
$$

$V_{d c}$ is the dc link voltage, $R_{m}$ and $R_{a}$ are the main and auxiliary winding resistances, $i_{m}$ and $i_{a}$ are the main and auxiliary winding currents, and $\lambda_{m}$ and $\lambda_{a}$ are the main and auxiliary winding flux linkages, respectively.

The load dynamics of the motor are expressed as

$$
\frac{d \omega_{r}}{d t}=\frac{T_{e}-B \omega_{r}-T_{L}}{J}
$$

where $\omega_{r}$ is the rotor speed, $B$ is the friction coefficient, $T_{L}$ is the load torque, and $J$ is the inertia of the rotor and load, respectively.

\section{Proposed Sensorless Control}

\section{A. Principle of Position Estimation}

The basic principle of the proposed sensorless control is illustrated in Fig. 3.

In an unsaturated magnetization case, the voltage equation for the main phase winding can be approximated from (1) as

$$
v_{m}=R_{m} i_{m}+L_{m}(\theta) \frac{d i_{m}}{d t}+i_{m} \frac{d L_{m}(\theta)}{d t}
$$

where $L_{m}$ is the angle dependent main phase self-inductance.

Assuming the motor is running at a constant speed, voltage equations at two sampling times for any two consecutive switch-on periods can be expressed respectively by

$$
\begin{aligned}
& v_{m}\left(t_{1}\right)=R_{m} i_{m}\left(t_{1}\right)+L_{m}\left(t_{1}\right) \frac{d i_{m}\left(t_{1}\right)}{d t}+i_{m}\left(t_{1}\right) \frac{d L_{m}\left(t_{1}\right)}{d t} \\
& v_{m}\left(t_{2}\right)=R_{m} i_{m}\left(t_{2}\right)+L_{m}\left(t_{2}\right) \frac{d i_{m}\left(t_{2}\right)}{d t}+i_{m}\left(t_{2}\right) \frac{d L_{m}\left(t_{2}\right)}{d t} .
\end{aligned}
$$

The voltage applied to main winding for each case is the dc bus voltage, i.e. $v_{m}\left(t_{1}\right)=v_{m}\left(t_{2}\right)=V_{d c}$. Assuming good

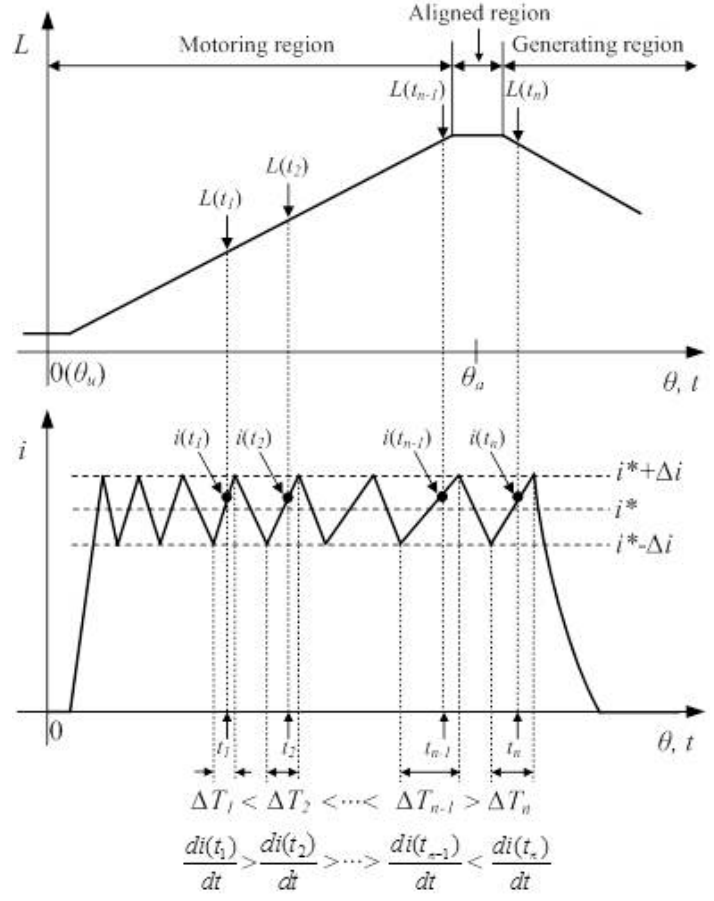

Fig. 3. Relationship between inductance and rate of change of current.

current regulation (hysteresis control employed herein), each instantaneous current at $t_{1}$ and $t_{2}$ is comparable to the reference value, i.e. $i_{m}\left(t_{1}\right) \approx i_{m}\left(t_{2}\right) \approx i^{*}$, which yields

$$
R_{m} i_{m}\left(t_{1}\right) \approx R_{m} i_{m}\left(t_{2}\right) .
$$

Assuming a non-saturated linear inductance case, the slope of the main phase inductance profile, $d L_{m}(\theta) / d t$ is constant in the motoring region. Therefore, the third terms of both (10) and (11) can be assumed to be the same:

$$
i_{m}\left(t_{1}\right) \frac{d L_{m}\left(t_{1}\right)}{d t} \approx i_{m}\left(t_{2}\right) \frac{d L_{m}\left(t_{2}\right)}{d t} .
$$

Considering (12) and (13), subtracting (11) from (10) ends up with

$$
L_{m}\left(t_{1}\right) \frac{d i_{m}\left(t_{1}\right)}{d t} \approx L_{m}\left(t_{2}\right) \frac{d i_{m}\left(t_{2}\right)}{d t} .
$$

From (14), following relationship between the rate of change of current and the phase inductance can be inferred:

1) Motoring region $\left(d L_{m} / d t>0\right)$

$$
\text { if } \frac{d i_{m}\left(t_{2}\right)}{d t}<\frac{d i_{m}\left(t_{1}\right)}{d t} \text {, then } L_{m}\left(t_{2}\right)>L_{m}\left(t_{1}\right)
$$

$: \mathrm{di}_{m} / \mathrm{dt}$ decreases as $\mathrm{L}_{m}$ increases.

2) Generating region $\left(d L_{m} / d t<0\right)$

$$
\text { if } \frac{d i_{m}\left(t_{2}\right)}{d t}>\frac{d i_{m}\left(t_{1}\right)}{d t}, \text { then } L_{m}\left(t_{2}\right)<L_{m}\left(t_{1}\right)
$$

: $\mathrm{di}_{m} / \mathrm{dt}$ increases as $\mathrm{L}_{m}$ increases.

3) Aligned and unaligned regions $\left(d L_{m} / d t=0\right)$

$$
\text { if } \frac{d i_{m}\left(t_{2}\right)}{d t}=\frac{d i_{m}\left(t_{1}\right)}{d t}, \text { then } L_{m}\left(t_{2}\right)=L_{m}\left(t_{1}\right)
$$

$: \mathrm{di}_{a} / \mathrm{dt}$ does not change since $\mathrm{L}_{m}$ remains constant. 
The rate of change of current for each switch-on time can be calculated by measuring switch-on time $\left(\Delta T_{o n}\right)$ and the current increment $(2 \Delta i)$ within a switch-on period as shown in Fig.3:

$$
\frac{d i_{m}}{d t}=\frac{2 \Delta i}{\Delta T_{o n}} .
$$

Since $\Delta i$ is known from the predefined hysteresis current band which is constant for all switching cycles, (15), (16), and (17) can be rewritten as

$$
\begin{aligned}
& \text { if } \Delta T_{1}>\Delta T_{2}, \text { then } L_{m}\left(t_{2}\right)>L_{m}\left(t_{1}\right) \\
& \text { if } \Delta T_{1}<\Delta T_{2} \text {, then } L_{m}\left(t_{2}\right)<L_{m}\left(t_{1}\right) \\
& \text { if } \Delta T_{2}=\Delta T_{1} \text {, then } L_{m}\left(t_{2}\right)=L_{m}\left(t_{1}\right) .
\end{aligned}
$$

Therefore, by comparing switch-on times for two consecutive PWM cycles, the aligned $\left(\theta_{a}\right)$ and unaligned $\left(\theta_{u}\right)$ positions can be detected. If $\Delta T_{n}>\Delta T_{n-1}$ for any two consecutive switching cycles, the rotor is still in the motoring region (positive inductance slope) and hence the main phase should remain energized. If $\Delta T_{n} \leq \Delta T_{n-1}$, then the rotor has reached the aligned position where commutation of the main phase should be established. Once the aligned position is detected, the unaligned position can be easily determined from the motor geometry (Fig. 1) such that they are shifted by $45^{\circ}$ each other. At low speed, the detected aligned position can be used as default turn-off $\left(\theta_{\text {off }}\right)$ angle, and turn-on $\left(\theta_{\text {on }}\right)$ angle can be adjusted to control dwell period with respect to operating speed and load. Fast sampling in hysteresis control is of importance so that the commutation should be initiated before the rotor enters the generating region significantly.

At high speed, however, turn-off angle needs to be advanced to avoid significant negative torque generation. In this case, the aligned position is first detected by monitoring transition of switch-on time vs. inductance relationship from (21) to (19), and then the proper turn-off angle can be adjusted based on the operating speed. Among the important advantages of the proposed sensorless method are: 1) Simple digital implementation without substantial computation or extra hardware is possible., 2) No pre-stored data for inductance profile or magnetization curves is required, 3) The voltage equation is not used for position estimation, and hence the accuracy of the estimation is not significantly affected by the effects of winding resistance and back-EMF.

\section{B. Digital Real-time Implementation}

A DSP controller has been used to implement the proposed sensorless algorithm as illustrated in Fig. 4 showing the waveforms of gate signal, main phase current, and timer counts. Two timers have been used to calculate the switch-on time and the motor speed and position.

1) Timer $1:$ (switch-on time calculation): Timer 1 is a CPU timer to calculate switch-on time. This timer counts by $10 \mathrm{MHz}$ clock frequency; hence, the switch-on time at each different switching cycle is calculated using

$$
\Delta T_{\text {on }}(n)=T C(n) \times(0.1 \mu s) .
$$

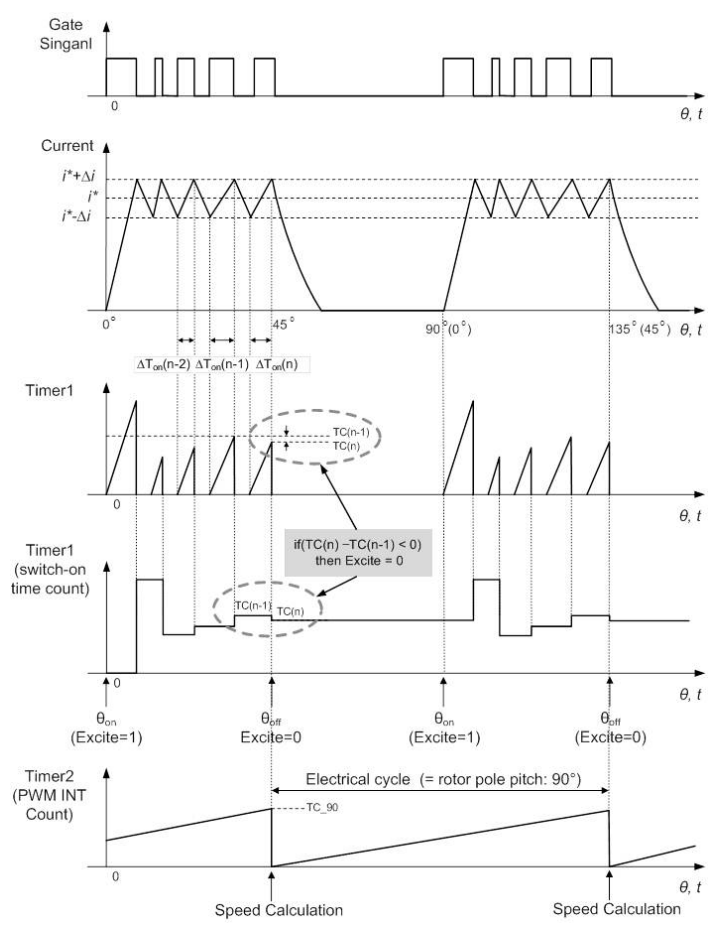

Fig. 4. Position estimation and sensorless control algorithm.

where $T C(n)$ is the total timer count for switch-on time at each different switching cycle. In hysteresis current control, when the main phase current falls below the lower hysteresis band limit, the switch is turned on. As soon as the switch is turned on, Timer 1 starts counting until the switch is turned off when the phase current reaches the upper hysteresis band limit. Total count value of Timer 1 for switch-on time is stored in the register and then Timer 1 is reset to zero for the next switching cycle. The timer begins to count again when the current reaches the lower hysteresis band limit and hence the switch is turned on. As shown in Fig. 4, the timer count value at each switching cycle, $T C(n)$ is compared with the one at the previous switching cycle, $T C(n-1)$ except for the first switchon time during the initial current buildup. As soon as the controller detects the instant when $T C(n)-T C(n-1) \quad 0$, the excitation of the main phase is terminated (Excite $=0$ ).

2) Timer 2 (Speed and position calculation): : Timer 2 measures time interval between two consecutive aligned $\left(45^{\circ}\right)$ positions-i.e. $90^{\circ}$ angular interval of rotor pole pitch-by counting PWM interrupt routine that occurs every $4 \mu \mathrm{s}(250 \mathrm{kHz})$. The measured time interval is used to calculate the speed and position of the rotor. As shown in Fig. 4, Timer 2 starts incrementing when the rotor is on the aligned position (Excite $=0$ ) until it reaches its maximum count at the next aligned position. Then, this timer resets to zero and starts counting again. The speed is calculated every time the aligned position is detected:

$$
\begin{aligned}
\omega_{r}= & \frac{d \theta}{d t}=\frac{90^{\circ}}{T C_{-} 90 \times 4 \mu s}(\mathrm{deg} / \mathrm{s}) \\
& =\frac{90^{\circ}}{T C_{-} 90 \times 4 \mu s} \times \frac{60}{360^{\circ}}(\mathrm{r} / \mathrm{min})
\end{aligned}
$$

where TC_90 is total count value of Timer 2 for the interval between the two aligned positions $\left(90^{\circ}\right.$ rotor pole pitch). 
Assuming the speed is constant at steady-state, the rotor position, $\theta$ within the phase commutation cycle $\left(0^{\circ}\right.$ to $\left.89^{\circ}\right)$ can be calculated by

$$
\theta=\operatorname{rem}\left(\frac{\text { Timer2_Count }}{\text { TC_90 }} \times 90^{\circ}+45^{\circ}, 90^{\circ}\right)(\text { deg })
$$

where Timer2_Count is an incremental count value of Timer 2 and the value of TC_90 is inherited from the previous speed calculation.

\section{DRIVE SySTEM CONTROL}

\section{A. Sensorless Starting}

The algorithm implemented for starting is similar to the one described in [3]. At standstill, when $S_{1}$ is turned on for a preset period of time to induce a large current pulse in the main phase winding. This current, along with the current through the auxiliary phase winding when $S_{1}$ is turned off, results in torque production and causes the rotor to move. Note that the number and period of the applied starting pulses are predetermined based on required starting torque. Once the motor starts, the controller executes the sensorless control algorithm. First, the main winding is excited regardless of the rotor position to find the aligned position, and after the aligned position is determined, the controller executes normal commutation of each phase by calculating the rotor position and speed. After the sensorless control algorithm is put into execution, and the motor is driven to the desired speed.

\section{B. Digital Hysteresis Current Control}

For inner-loop current control, hysteresis current control has been employed. Among the main advantages of hysteresis current control are simplicity, fast response, and robustness to system parameter perturbation. The dynamic performance is limited only by switching speed and load time constant, which makes hysteresis current control suitable for parameter insensitive sensorless control. However, unknown switching frequency may lead to increased acoustic noise. For digital implementation, fast sampling is necessary in order to minimize the response delay and tracking error and hence to achieve performance comparable to analog implementation. In the considered experimental setup, $250 \mathrm{kHz}$ sampling frequency is utilized

\section{Main Control Algorithm}

The proposed sensorless control has been implemented in a 32-bit $100 \mathrm{MHz}$ fixed-point digital processor (DSP) controller and its software implementation is illustrated using flowcharts in Fig. 5 and Fig. 6. Fig. 5(a) shows a flowchart for the main function of the drive control algorithm. After initialization of DSP, starting and sensorless control are put into execution in sequence. The sensorless control algorithm is executed every PWM interrupt routine as shown in Fig. 5(b). The PWM routine starts off monitoring the rotor position to determine whether to initiate the excitation of the main winding, followed by the current control loop. Timer 2 counts every time this routine is executed.

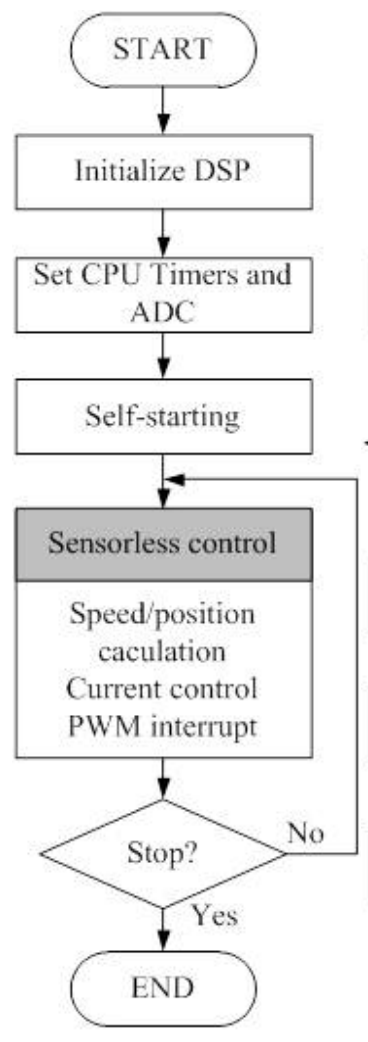

(a)

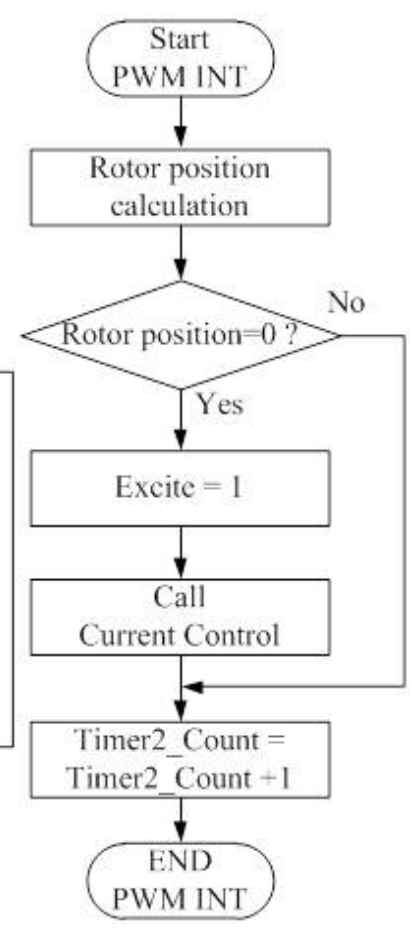

(b)
Fig. 5. Flowcharts for (a) main function algorithm and (b) PWM interrupt routine.

The current control loop shown in Fig. 6 executes hysteresis control, switch-on time calculation, and speed calculation. When the main winding current goes below the lower hysteresis limit $\left(i^{*}-\Delta i\right)$, the switch is turned on. Timer 1 is reset and starts incrementing. When the main winding current exceeds the upper hysteresis limit $\left(i^{*}+\Delta i\right)$, the switch is turned off and the final count of Timer 1 is stored and compared with the previously stored timer count value for the previous switching cycle. Keep on comparing until $T C(n)-T C(n-1) \leq 0$. The rotor is now in the aligned position, where phase excitation should be extinguished immediately (Excite $=0$ ). Then, the rotor speed is calculated from Timer 2's value and then Timer 2 is reset to zero.

To prevent unwanted early termination of excitation due to unfiltered noise or inductance nonlinearity, the excitation is maintained until the rotor reaches the position that is shifted $30^{\circ}$ from the unaligned position.

\section{Simulation Results}

Fig. 7 shows simulation results for the proposed sensorless method implemented on the single-switch-based SRM running at $1800 \mathrm{r} / \mathrm{min}$ with $4 \mathrm{~A}$ current command. Waveforms of the main phase inductance, gate signal for switch S1, main phase current, timer count for switch-on time, and estimated rotor position (electrical degree) are plotted. The timer count for each switch-on time varies with respect to the rotor position such that it increases along with the positive inductance slope but decreases with the negative inductance slope. Hence, the aligned position is detected from the transition of the timer 


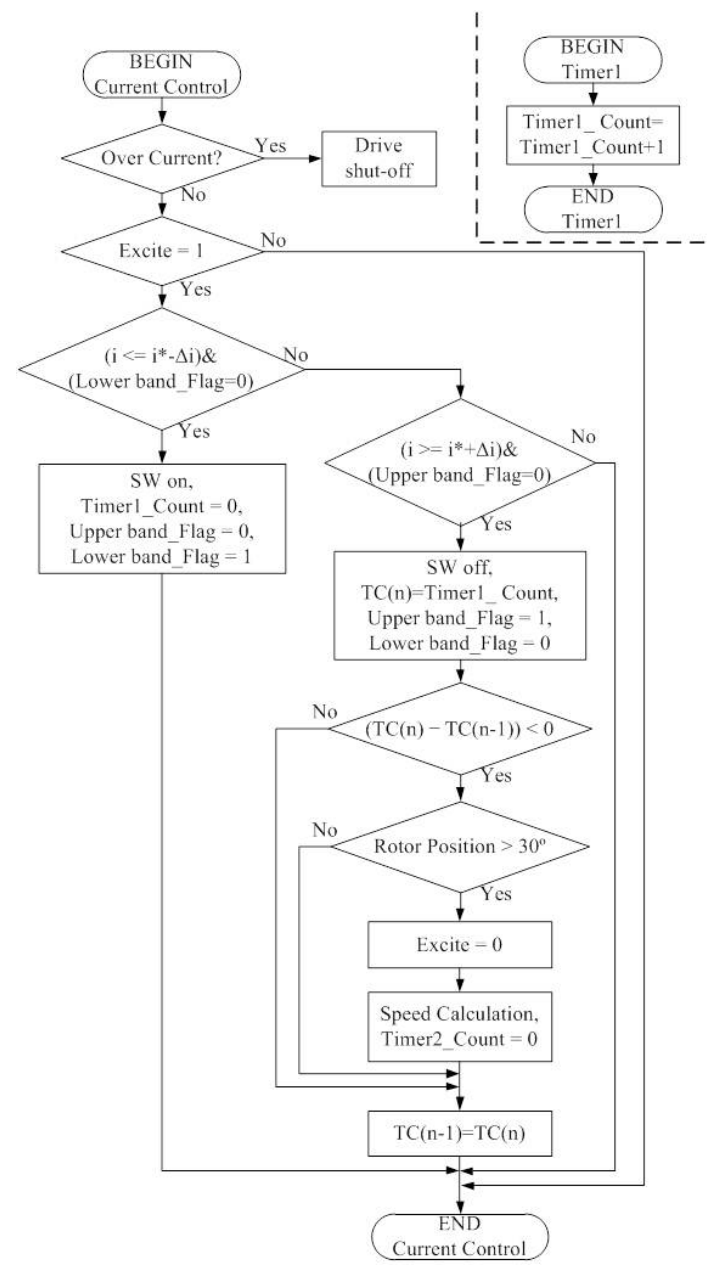

Fig. 6. Flowchart for current control loop.

count from incrementing to decrementing count. It can be seen that the timer count correlates with the actual inductance profile and hence with the estimated rotor position.

\section{EXPERIMENTAL RESULTS}

Fig. 8 shows a block diagram of the experimental drive system including the motor, drive electronics, and controller. Drive control and sensorless algorithm is implemented in realtime using a TMS320F2808 DSP controller with $250 \mathrm{kHz}$ sampling frequency for the main phase current. The dc link voltage is approximately $155 \mathrm{~V}$ from the rectified ac main. The power switching devices for the converter are realized with an ultra-fast IGBT and fast-recovery diodes.

The execution of the sensorless starting is shown in Fig. 9. The large spike in the main phase current indicates the induced current pulse by the applied starting pulse with a preset period of time $(1.2 \mathrm{~ms})$, which causes the rotor to rotate. The sensorless algorithm is invoked after $165 \mathrm{~ms}$ to detect the aligned position. The starting may be challenging when the rotor is initially either at aligned position or midpoint between aligned and unaligned positions. In that case, multiple pulses should be applied to ensure the sufficient torque production in both main and auxiliary windings.

Experimental results for sensorless operation at steady-state are shown both in Fig. 10 and Fig. 11. Fig. 10 shows the

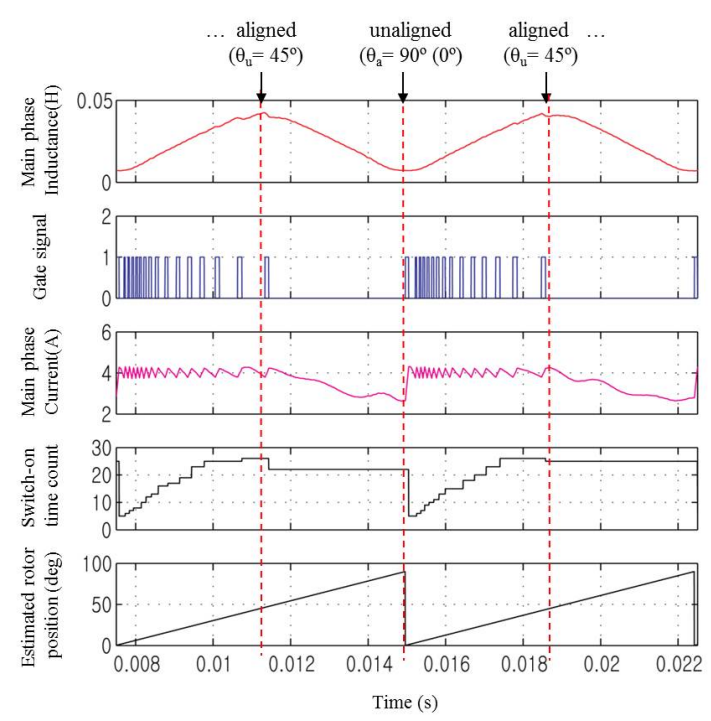

Fig. 7. Simulation results for the rotor position estimation.

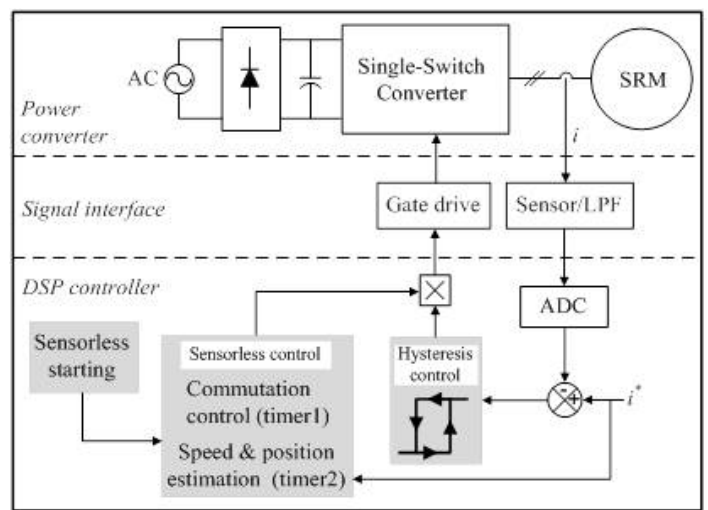

Fig. 8. Block diagram for experimental drive system.

winding current, two hall sensor signals, and gate signal. In the experimental motor, two hall sensors are mounted above two adjacent stator poles which are $45^{\circ}$ shifted each other. Both rising and falling edges of the hall sensor1 signal indicate the unaligned position $\left(0^{\circ}\right)$, and both rising and falling edges of the hall sensor 2 signal indicate the aligned position $\left(45^{\circ}\right)$. Note that only the estimated rotor position and speed are used for drive control, while the measured hall sensor signals are only a reference to indicate the correct motoring position. From Fig. 10 , it can be seen that phase excitation is correctly achieved in the motoring region and the estimated aligned and unaligned positions are quite comparable to the actual ones detected by the hall sensors. The current spike at the beginning of excitation around the unaligned position is due to regenerative energy from the auxiliary winding.

\section{CONCLUSIONS}

A new parameter insensitive sensorless control is proposed and experimentally demonstrated using the single-controllableswitch-based SRM drive. The key conclusions of this paper are:

1) The proposed scheme is very simple to implement requiring measurement of only phase current and minimal computation, and does not need any pre-stored lookup 


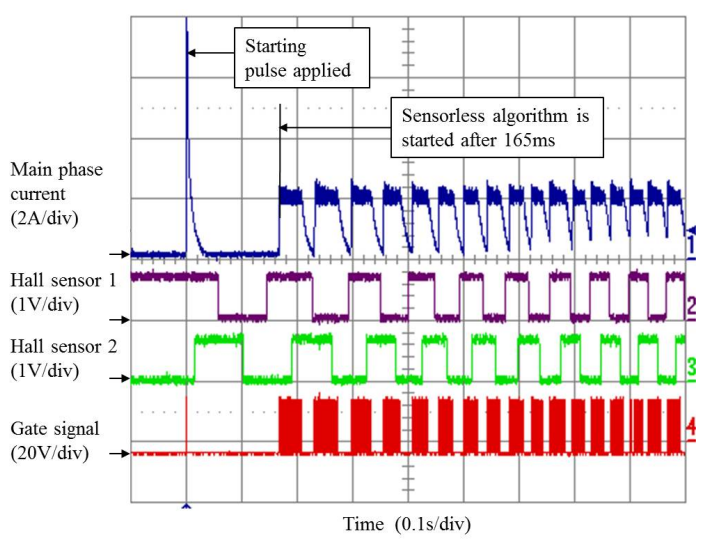

Fig. 9. Sensorless motor starting from standstill.

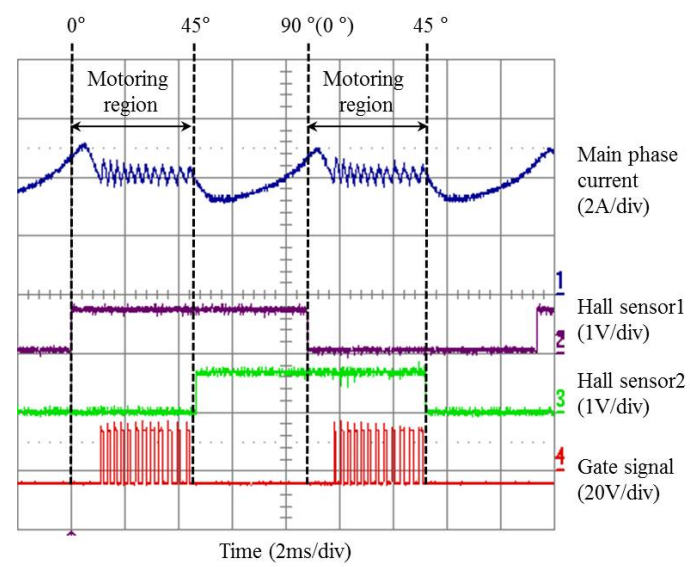

Fig. 10. Measured waveforms when the motor is running at $1800 \mathrm{r} / \mathrm{min}$.

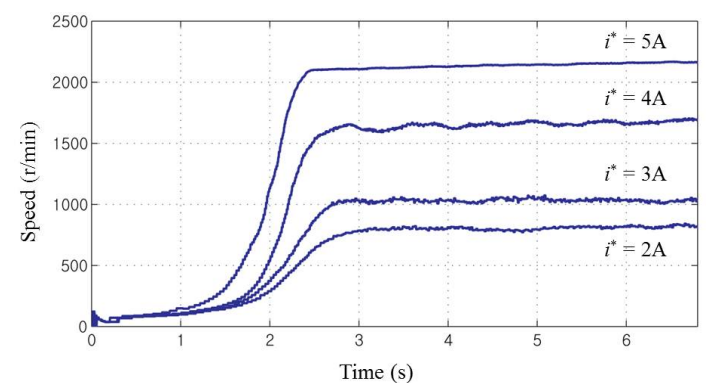

Fig. 12. Measured motor speed from startup to steady-state at different operating speeds.

table or extra hardware, which makes this scheme inherently suitable for low cost deployment.

2) The method is robust to the presence of system parameter variations since it does not employ an analytical inductance model or a model-based estimator which is sensitive to the estimation of the motor parameters.

3) Although the method is implemented using a two-phase SRM with the single switch converter, it can also be implemented with any multi-phase SRM with the conventional asymmetric converter.

4) It does not limit low speed operation which is quite challenging in many flux or back-EMF based methods.

5) It is inherently suitable for current controlled operation rather than single-pulse operation where chopping is not possible.

6) The drive system has only one controllable switch and two diodes in total for driving the two-phase SRM, hence making it very compact and inexpensive. The considered SRM drive in conjunction with the proposed sensorless scheme can offer an attractive solution for brushless variable speed drives in low-cost, high-volume applications such as home appliances.

\section{ACKNOWLEDGMENT}

This paper was supported by Wonkwang University in 2011.

\section{REFERENCES}

[1] R. Krishnan, Switched Reluctance Motor Drives: Modeling, Simulation, Analysis, Design, and Applications, CRC Press, pp. 385-393, 2001.

[2] R. Krishnan, A. M. Staley, and K. Sitapati, "A novel single-phase switched reluctance motor drive system," in Proc. IEEE-IECON, pp. 1488-1493, 2001.

[3] R. Krishnan, S. Y. Park, and K. S Ha, "Theory and operation of a four-quadrant switched reluctance motor drive with a single controllable switch-the lowest cost four-quadrant brushless motor drive," IEEE Trans. Ind. Appl., Vol. 41, No. 4, pp. 1047-1055, Jul./Aug. 2005.

[4] J. Kim and R. Krishnan, "novel two-switch based switched reluctance motor drive for low-cost applications," in Proc. IEEE-IAS Annu. Meeting, pp. 2218-2225, 2007.

[5] C. Lee, R. Krishnan, and N. S. Lobo, "Novel two-phase switched reluctance machine using common-pole e-core structure: concept, analysis, and experimental verification," in Proc. IEEE-IAS Annu. Meeting, pp. 2210-2217, 2007.

[6] J. P. Lyons, S. R. MacMinn, and M. A. Preston, "Flux/current methods for SRM rotor position estimation," Proc. IEEE-IAS Annu. Meeting, pp.482-487, 1991.

[7] N. H. Mvungi and J. M. Stephenson, "Accurate sensorless rotor position detection in an SR motor," in Proc.s European Power Electron. Conf., Vol. I, pp. 390-393, 1991. 
[8] K. M. Richardson, C. Pollock, and J. O. Flower, "Design and performance of a rotor position sensing system for a switched reluctance machine propulsion unit," in Proc. IEEE-IAS Annu. Meeting., pp.168$173,1996$.

[9] H. Y. Yang, J. G. Kim, Y. C. Lim, S. K. Jeong, and Y. G. Jung, "Position detection and drive of a toroidal switched reluctance motor(TSRM) using search coils," IEE Proc. Electric Power Appl., pp.377-384, 2004.

[10] I. Husain, S. Sodhi, and M. Ehsani, "A sliding mode observer basedcontroller for switched reluctance motor drives," in Proc. IEEE-IAS Annu. Meeting, pp. 635-643, 1994.

[11] Y. J. Zhan, C. C. Chan, and K. T. Chau, "A novel sliding-mode observer for indirect position sensing of switched reluctance motor drives," IEEE Trans. Ind. Electron., Vol. 46, pp. 390-397, Apr. 1999.

[12] F. Blaabjerg, L. Christensen, S. Hansen, J. P. Kristofferson, and P. O Rasmussen, "Sensorless control of a switched reluctance motor with variable-structure observer," Electromotion, Vol. 3, No. 3, pp. 141-152, Jul. 1996.

[13] A. D. Cheok and N. Etugrul, "High robustness of an sr motor angle estimation algorithm using fuzzy predictive filters and heuristic knowledgebased rules," IEEE Trans. Ind. Electron., Vol. 46, pp.904-916, Oct. 1999.

[14] E. Mese and D. A. Torrey, "An Approach for sensorless position estimation for switched reluctance motors using artifical neural networks," IEEE Trans. Power Electron., pp.66-75, Jan. 2002.

[15] S. Paramasivam, S. Vijayan, M. Vasudevan, R. Arumugam, and R. Krishnan, "Real-time verification of ai based rotor position estimation techniques for a $6 / 4$ pole switched reluctance motor drive," IEEE Trans. Magn., Vol. 43, No. 7, pp. 3209-3222, Jul. 2007

[16] G. Suresh, B. Fahimi, K. M. Rahman, and M. Ehsani, "Inductance based position encoding for sensorless SRM drives," in Proc. IEEE Power Electronics Specialists Conf., Vol. 2, pp. 832-837, 1999.

[17] H. Gao, F. R. Salmasi, and M. Ehsani, "Inductance model-based sensorless control of the switched reluctance motor drive at low speed," IEEE Trans. Power Electron., Vol. 19, pp. 1568-1573, Nov. 2004.

[18] S. R. MacMinn, W. J. Rzesos, P. M. Szczesny, and T. M. Jahns, "Application of sensor integration techniques to switched reluctance motor drives," IEEE Trans. Ind. Appl., Vol. 28, No. 6, pp. 1339-1344, Nov./Dec. 1992.

[19] M. Ehsani, I. Husain, and A. Kulkarni, "Elimination of discrete position sensor and current sensor in switched reluctance motor drives," IEEE Trans. Ind, Appl., Vol. 28, No.1, pp. 128-135, Jan./Feb.1992.

[20] P. P. Acarnley, R. J. Hill, and C. W. Hooper, "Detection of rotor position in stepping and switched reluctance motors by monitoring of current waveforms," IEEE Trans. Ind. Electron., Vol. 32, No. 3, pp. 215-222, Aug. 1985.

[21] S. K. Panda and G. A. J. Amaratunga, "Analysis of the waveform detection technique for indirect rotor position sensing of switched reluctance motor drives," IEEE Trans. Energy Convers., Vol. 6 , No. 3, pp. 476-483, Sep. 1991.

[22] G. Gallegos-Lopez, P. C. Kjaer, and T. J. E. Miller, "A new sensorless method for switched reluctance motor drives," IEEE Trans. Ind. Appl., Vol. 34, No. 4, pp. 832-840, Jul./Aug. 1998.

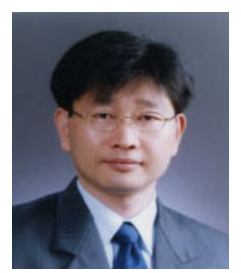

Hyong-Yeol Yang was born in Chonnam, Korea in 1969. He received his B.S. M.S. and Ph.D. in Electrical Engineering from Chonnam National University, Gwangju, Korea in 1993, 1998 and 2004 respectively. His research experience includes work done with Hyundai Motor Company, the Regional Research Center for High-quality Electric Component and Systems at Chonnam National University, Honam University and G-Auto Co., Korea. He has also done visiting research at Virginia Tech., USA. He is currently a full time lecturer in the department of Electrical Engineering at Honam University, Gwangju, Korea. His main research interests are in the areas of fuzzy logic control, design and drives of electric machines, and applications using microcontrollers.

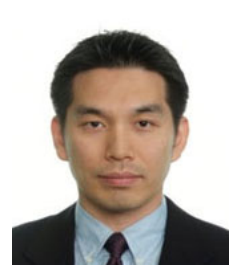

Jaehyuck Kim was born in Seoul, Korea, in 1973. He received his B.S. degree from Hanyang University, Seoul, Korea in 1999, M.S. degree from University of Wisconsin at Madison, USA in 2004, and Ph.D. from Virginia Polytechnic Institute and State University, Blacksburg, in 2010 respectively, all in electrical engineering. From 1998 to 2000, he worked for Underwriters Laboratory Inc, USA, as an engineer. He also worked for Ramu Inc. as a senior engineer in 2011. Dr. Kim is currently an assistant professor at Wonkwang University. His research interests have been concerned with power electronic energy conversions and variable speed drives both in domestic and industrial applications. Dr. Kim was the recipient of the First Prize Paper Award from the Industrial Drives Committee of the IEEE Industrial Applications Society in 2006.

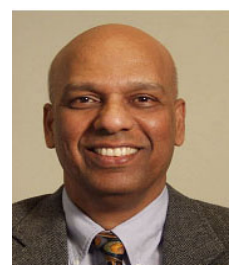

R. Krishnan received the Ph.D. degree in electrical engineering from Concordia University, Montreal, QC, Canada. He is currently a Professor at Virginia Polytechnic Institute and State University, Blacksburg, where he also directs the Center for Rapid Transit Systems, pursuing unique, safe, high-speed, energy efficient, and personal electric transit solutions. He has been a consultant to more than 18 companies in the USA. His inventions constituted founding technologies for two startup companies in linear and rotating switched reluctance motor drives technologies respectively, in the U.S. Apart from founding these companies, he served as the founding Chief Technical Officer for some time to both and Chairman of the Board of Directors for one. His research interests are analysis, design, and innovations in electric motor drives, electric machines, and power converters for motor drives and applied control. Dr. Krishnan is a Distinguished Lecturer of the IEEE Industrial Electronics Society. $\mathrm{He}$ is an elected Senior AdCom Member of the IEEE Industrial Electronics Society and served as Vice President (Publications) from 2002 to 2005. He was the recipient of six Best Paper Prize Awards from the IEEE Industry Applications Society (five from the Industrial Drives Committee and one from the Electric Machine Committee), the First Prize Paper Award from the IEEE TRANSACTIONS ON INDUSTRY APPLICATIONS and the Best Paper Award from the IEEE Industrial Electronics Magazine in 2007, and the IEEE Industrial Electronics Society's Dr. Eugene-Mittelmann Achievement Award for outstanding technical contributions to the field of industrial electronics. 